\title{
Uma mulher nas entrelinhas do Concílio Vaticano II: análise de um fragmento eclesiológico de Edith Stein
}

Eduardo Dalabeneta

\section{Resumo}

Aproxima-nos do cinquentenário do Concílio Vaticano II e naturalmente fazemos memória. Na verdade, em 1962 uma "onda" de personagens, testemunhos e movimentos derramaram-se na praia conciliar deixando ali suas contribuições, que foram recolhidas, em maior ou menor proporção, nas páginas dos documentos. Recordamos do Movimento Bíblico, do Movimento Litúrgico, do Movimento Ecumênico, da Ação Católica... Dentre os personagens que contribuíram na sua realização recordamos de João XXIII, Paulo VI, dos teólogos Rahner, Congar, Ratzinger... Contudo, não podemos resumir essa "onda" apenas nesses movimentos e nesses personagens. Certamente, esses foram os catalisadores, mas nessa "onda" outros nomes ainda permanecem desconhecidos. Por isso, no limiar das comemorações, merece destaque, Edith Stein, na Igreja, Santa Teresa Benedita da Cruz, a judia carmelita. Surpresa para muitos, a sintese dramática de nosso século $X X$, aparece de forma anônima nas entrelinhas do Concílio Vaticano II. Para confirmar essa certeza, esse ensaio apresentará apontamentos sobre a eclesiologia em Edith Stein e o colocará em paralelo com textos conciliares.

Palavras-chave: Edith Stein; Eclesiologia; Vaticano II. 


\begin{abstract}
As we approach the fiftieth anniversary of the Second Vatican Council, we naturaly remind this fact. Truly, in 1962 a "wave" of characters, testimonies and movements shed on the beach and left there contributions that have been collected to a greater or lesser extent, in the pages of the documents. We recall the Biblical Movement, Liturgical Movement, the Ecumenical Movement, Catholic Action ... Among the characters who contributed to its realization, we remind of John XXIII, Paul VI, theologians Rahner, Congar, Ratzinger ... However, we cannot summarize this "wave" only in these movements and characters. Certainly, these were the catalysts, but other characters of this "wave" remain unknown. Therefore, at the threshold of the celebration, Edith Stein, in the Church, and St. Teresa Benedicta of the Cross, the Jewish Carmelite deserve to be highlighted. As a surprise to many, the dramatic synthesis of the 20th century appears anonymously between the lines of Vatican II. To confirm this assurance, this paper provides insights into the ecclesiology of Edith Stein and place it in parallel with the respective texts.
\end{abstract}

Keywords: Edith Stein; Ecclesioloy; Second Vatican.

A figura de Edith Stein (1891-1942) nos é conhecida: judia, filósofa, pedagoga, carmelita, mártir e santa. Contudo, a grande maioria tem conhecimento apenas o seu itinerário espiritual, sem imaginar que ela é uma figura polivalente e cativante. Reunindo todos os seus escritos, alcançamos a marca de mais de 5000 páginas, distribuídos entre textos espirituais, antropológicos, pedagógicos, filosóficos e teológicos ${ }^{1}$. Porém, muito pouco desta vasta obra é conhecida ou está sendo pesquisada.

Em 1938, com a morte de Husserl, filósofo e cristão luterano, pensador que iniciou Edith Stein na ciência filosófica, ela escreve uma carta a uma amiga, Aldegonde Jaegerschmid, onde afirma:

\footnotetext{
${ }^{1}$ Para essa afirmação utilizamos como referência a publicação da editora Editorial Monte Carmelo, da Espanha, que organizou as obras completas de Edith Stein em cinco volumes, classificando-os em Escritos autobiográficos e cartas (Volume 1), Escritos filosóficos - etapa fenomenológica (Volume 2), Escritos filosóficos - etapa do pensamento cristão (Volume 3), Escritos antropológicos e pedagógicos (Volume 4) e Escritos espirituais (Volume 5).
} 


\begin{abstract}
Nunca gostei de pensar que a misericórdia de Deus fosse apenas aos confins da Igreja visível. Deus é a verdade. Quem procura a verdade procura Deus, quer o saiba ou não².
\end{abstract}

Nessa frase de Edith Stein encontramos o ponto de partida para interpretar e sistematizar sua eclesiologia, da fonte aos frutos. Porém, ainda estamos a 24 anos do Concílio Vaticano II, que recordou que a norma da fé é a norma da vida (Lex credendi - Lex vivendi) e promoveu o aggiornamento da Igreja. Por isso, essa afirmação não brota dos documentos conciliares ou da teologia do "cristão anônimo" de Rahner". Aquilo que será proclamado "sobre os telhados" anos mais tarde já é realidade pensada, vivida e testemunhada naquela carta.

Edith Stein está inserida num contexto histórico e eclesial particular. A sociedade de seu tempo vive em meio a conflitos ( $1^{\mathrm{a}}$ Guerra Mundial, Revolução Russa, conflitos por independência nas colônias européias) e de avanços econômicos que enriquecem poucos e empobrecem a muitos. Questionada por esta mesma sociedade, a Igreja da época continuava a entender-se como "sociedade perfeita" e adotava uma postura excludente quando utilizava a expressão patrística extra ecclesiam nulla salus.

Mesmo sem ter cursado teologia acadêmica, a eclesiologia de Edith Stein revive as intuições dos Santos Padres e dos Doutores medievais, mas, a judia "convertida" vai um pouco mais além, recorda que a comunidade cristã carrega a experiência de fé do povo judeu, do povo eleito, filhos de Abraão e herdeiros da mesma herança. Mesmo depois da sua conversão ${ }^{4}$ ao cristianismo, acontecida em 1922, a influência da sua origem judaica envolve seu pensamento, percorrendo suas pesquisas. Em Edith temos um exemplo contemporâneo daquilo que aconteceu com os discípulos de Jesus. Pedro, Paulo e os demais morreram como seguidores de Cristo sem anular suas vidas e suas raízes judaicas.

\footnotetext{
${ }^{2}$ SCIADINI, P., Vida e novena - Santa Teresa Benedita da Cruz. Edições Carmelitanas, São Roque, s/d, p. 23.

${ }^{3}$ RAHNER, K., Curso fundamental da fé. Paulinas, São Paulo, 1989, pp. 69-91.

${ }^{4}$ Não se aplica à experiência de Edith a visão clássica de conversão ligada a perda e descontinuidade. No caso dela, conversão foi um voltar eterno cetro (Cf. BUBER, M., Eu e Tu. Centauro, São Paulo, 2006, p. 105). Nesse caso, ao se tornar cristã, Edith não abandona suas raízes judaicas, pelo contrário, redescobre sua essência e a vive intensamente. Sua conversão foi um permitir-se ser tocada pelo hebreu Jesus de Nazaré, pois a conversão consiste em reconhecer novamente o centro e a ele voltar-se novamente (Cf. BUBER, M., Eu e Tu. Centauro, São Paulo, 2006, p. 118).
} 
Assim, iniciamos agora uma exegese nos documentos do Concílio Vaticano II, sob o enfoque eclesiológico, estabelecendo paralelos com o pensamento da judia carmelita, com o objetivo de responder a seguinte pergunta: estaria Edith Stein, presente com seu pensamento, nas entrelinhas do Concílio Vaticano II?

\section{Ecclesia-Qahãl}

Nossa filósofa nunca se preocupou em sistematizar o que pensava ser a Igreja ou produzir um tratado sobre esse tema. Sua eclesiologia está espalhada em suas obras e cartas. Contudo, suas intuições são frutos das suas experiências vivenciais e dos processos fenomenológicos ${ }^{5}$. Por isso, a origem judaica e sua formação filosófica são coordenadas que precisam ser levadas em consideração quando se decide entrar em contato com suas pesquisas.

O resultado desse encontro é que Edith oferece dados importantes sobre a origem, a identidade e a missão da Igreja. Isso acontece porque nela duas tradições religiosas se encontram, Judaísmo-Cristianismo, onde a afirmação de uma não exige a negação da outra. Entre a comunidade cristã e o povo judeu existe pontos de aproximação, que embora distintos na existência, partilham da mesma fonte. A Ecclesia de Jesus é a realização da Qahãl judaica:

A bênção e a distribuição do pão e do vinho faziam parte do rito da ceia pascal. Mas, um e outro, recebem aqui um sentido inteiramente novo. Aí se origina a vida da Igreja. Sem dúvida, somente em Pentecostes surge ela como comunidade espiritual e visível. Na Ceia, porém, se realiza o enxerto do sarmento no tronco, que torna possível a efusão do Espírito ${ }^{6}$.
Eis porque a Igreja não pode esquecer que recebeu a Revelação do Antigo Testamento por meio daquele povo com que Deus, na sua inefável misericórdia, se dignou estabelecer a Antiga Aliança, como não pode se esquecer que se alimenta da raiz da boa oliveira, na qual foram enxertados os ramos da oliveira selvagem que são os gentios ${ }^{7}$.

O povo de Israel e os discípulos de Jesus comungam de um patrimônio comum $(\mathrm{Rm} 9,4)$ e estão unidos num mesmo plano de salvação ${ }^{6}$ (mesmo

\footnotetext{
${ }^{5}$ A ferramenta científica utilizada por Edith Stein em suas pesquisas é a sua formação fenomenológica. Combatendo ao subjetivismo cognitivo, a fenomenologia parte dos fenômenos para, a partir deles, aproximar-se de um conhecimento objetivo. Assim, avança-se de uma descrição da realidade até a delimitação da estrutura ontológica do ser (Cf. BELLO, A.A. A fenomenologia do ser humano traços de uma filosofia no feminino. EDUSC, Bauru, 2000, pp. 81-90).

${ }^{6}$ Cf. CONCÍLIO ECUMÊNICO VATICANO II. "Constituição Dogmática Lumen Gentium sobre a
} 
tronco). Por isso, para Edith não há conflito na passagem da vida judaica à vida cristã: Você não imagina como sou feliz por pertencer à raça eleita ${ }^{7}$, diz ela numa carta.

Sabemos, pelas narrativas evangélicas, que o Cristo orou como um judeu crente e fiel a Lei ${ }^{10}$.

Não é a guerra de extermínio contra o sangue judeu um insulto à Sacratíssima Humanidade do Nosso Redentor, à Santíssima Virgem e aos Apóstolos? ${ }^{11}$.
[...] Em primeiro lugar aquele povo que foi objeto das alianças e das promessas, e do qual nasceu Cristo segundo a carne ${ }^{12}$.

Recorda-se também que do povo hebreu procedem os apóstolos, fundamentos e colunas da Igreja, como também números dos primeiros discípulos, que anunciaram o Evangelho pelo Mundo ${ }^{13}$.

Jesus é um fiel judeu que identifica em seu povo valores soteriológicos universais (ele faz um processo exegético) e anuncia-os como revelação, segundo sua capacidade de compreender, afirmando que estes valores são dons divinos ${ }^{12}$ (estabelece nova hermenêutica) e exige a vivência deles no cotidiano das relações (espiritualidade): Tudo o que necessitamos para sermos acolhidos na comunhão dos espiritos bem-aventurados está contido nos sete pedidos do "Pater noster"

Num tempo em que imperava na Igreja um anti-semitismo teológico, Edith enfrenta essa postura excludente no plano intelectual e também vivencial, defendendo que é necessário voltar às origens judaicas da Igreja como pressuposto fundamental para entender a própria identidade, pois foi o povo judeu quem deu à humanidade Jesus e é por esse mesmo povo que nos vem o dom da salvação (Jo 4,22) no qual os discípulos de Cristo são enxertados: quis congregá-los na Santa Igreja, a qual, já prefigurada desde a origem do

Igreja”. In Documentos do Concílio Ecumênico Vaticano II, $3^{\text {a }}$ ed., Paulus, São Paulo, 2004, p. 123. Ao longo do artigo utilizaremos a sigla LG seguido do número do parágrafo (LG 16).

${ }^{7}$ STEIN, E., O mistério do natal. EDUSC, Bauru, 1999, p. 5.

${ }^{8}$ STEIN, E. A oração da Igreja. Agir, Rio de Janeiro, 1958, p. 23.

${ }^{9}$ STEIN, E., Carta ao papa Pio XI sobre a perseguição aos judeus. Münster, 12 de abril de 1933. Disponível em: <http://www.ifen.com.br/monografia/cynthialeite.pdf >. Acessado em 15 de julho de 2011.

${ }^{10}$ LG 16.

${ }^{11}$ NA 4.

${ }^{12}$ RATZINGER, J., Jesus de Nazaré. Planeta, São Paulo, 2007, p. 25.

${ }^{13}$ STEIN, E. A oração da Igreja. Agir, Rio de Janeiro, 1958, p. 32. 
mundo e preparada admiravelmente na história do povo de Israel e na antiga Aliança, foi manifestada pela efusão do Espírito, e será consumada em glória no fim dos séculos ${ }^{14}$.

\section{Sponsa Christi}

Para Edith o laço que une Jesus aos seus discípulos cria uma relação diferente. Individualmente cada um é chamado de amigo (Jo 15,12-17), mas a assembleia convocada e reunida (Ecclesia-Qahãl) vive com o seu Senhor uma relação esponsal: fidelidade, universalidade e doação total (Ef 5,24). Por isso, para nossa teóloga, a comunidade dos discípulos é Sponsa Christi ${ }^{15}$. Esse é o fundamento ontológico da Igreja.

Aqui ainda não está a novidade do seu pensamento, visto que inúmeros textos neotestamentários afirmam o mesmo (Gl 4,26; Ap 12,17). Porém, o que Edith quer propor é que existe na Igreja uma dimensão materna que faz parte da sua identidade: A Igreja é mãe dos remidos ${ }^{16}$. Os filhos de Deus são seus filhos $(\mathrm{Rm} 8,15)$.

Para ela não é por acaso que a figura da mulher prefigura as relações internas e externas da comunidade. A Igreja, o Reino de Deus já presente, é comparado por Jesus com figuras femininas:

Quis reunir os teus filhos dispersos como a galinha reúne os pintinhos debaixo das asas (Mt 23,37) [...] O reino é semelhante a mulher que toma uma medida de fermento e junta com duas medidas de trigo (Mt 13,33) [...] Quando a mulher encontrou a dracma perdida, chamou as amigas e disse: alegrem-se comigo (Lc 15,9).

Para a teóloga, as características essenciais da maternidade humana são propriedades ontológicas também da Igreja:

A atitude da mulher tem em vista o pessoal-vivente e visa o todo. Cuidar, velar, conservar, alimentar e promover ao crescimento: esse é o seu desejo natural, genuinamente maternal ${ }^{17}$.

\footnotetext{
${ }^{14}$ LG 2.

${ }^{15}$ STEIN, E., A mulher - sua missão segundo a natureza e a graça. EDUSC, Bauru, 1999, p. 263.

${ }^{16}$ STEIN, E., A mulher - sua missão segundo a natureza e a graça. EDUSC, Bauru, 1999, p. 263.

${ }^{17}$ STEIN, E., A mulher - sua missão segundo a natureza e a graça. EDUSC, Bauru, 1999, p. 57.
} 
[...] seu modo de conhecimento não é tanto o dissecador-conceitual e sim o caminho do concreto, observador, sensitivo. Essa disposição habilita a mulher à função de assistente e de educadora de seus filhos; mas essa atitude básica não vale só para eles, assim ela se dirige também ao homem e a todos os seres que entram em contato com ela ${ }^{18}$.

Para explicar essa maternidade universal da Igreja, Edith afirma que todo ser humano é remido, a Igreja é a humanidade remida ${ }^{19}$. Para ela, o mistério pascal de Cristo, da encarnação à redenção, penetrou todos os homens e mulheres, de todos os tempos, de todos os povos e de todas as crenças, conferindo-lhes um dom ontológico de efeito soteriológico, que é ponto angular da história universal ${ }^{20}: O$ restabelecimento da filiação divina constitui a finalidade imediata da redenção [...] Pela obra da salvação de Jesus Cristo, o ser humano ganhou o retorno à filiação divina ${ }^{21}$.

O criador do gênero humano encarnandose concede-nos a sua divindade. Por causa dessa obra maravilhosa o Redentor veio ao mundo. Na encarnação, Deus se tornou Filho do homem, para que os homens se tornassem filhos de Deus. Um de nós rompeu o laço da filiação divina, e um de nós devia reatar o laço. Nenhum da antiga e enferma raça podia fazêlo. Devia ser um rebento novo, sadio e forte. Tornou-se um de nós, e mais que isso: um conosco [...] Mas veio para tornar-se conosco um corpo místico ${ }^{24}$.
Veio, pois, o Filho, enviado pelo Pai, que ainda antes da criação do mundo nos escolheu nele e nele nos predestinou à filiação divina ${ }^{25}$.

Com efeito, sua humanidade, na unidade do Verbo, foi instrumento da nossa salvação ${ }^{26}$.

O Filho de Deus, unindo a si a natureza humana e vencendo a morte com a sua própria morte eressurreição, remiu ohomem, transformando-o em nova criatura ${ }^{27}$.

\footnotetext{
${ }^{18}$ STEIN, E., A mulher - sua missão segundo a natureza e a graça. EDUSC, Bauru, 1999, p. 58.

${ }^{19}$ STEIN, E., A mulher - sua missão segundo a natureza e a graça. EDUSC, Bauru, 1999, p. 262.

${ }^{20}$ Cf. STEIN, E., O mistério do natal. EDUSC, Bauru, 1999, p. 30.

${ }^{21}$ STEIN, E., A mulher - sua missão segundo a natureza e a graça. EDUSC, Bauru, 1999, p. 215.

${ }^{22}$ STEIN, E., O mistério do natal. EDUSC, Bauru, 1999, p. 19.

${ }^{0} \mathrm{LG} 3$.

${ }^{24}$ CONCÍlIO ECUMÊNICO VATICANO II. "Constituição Sacrosanctum Concilium sobre a Sagrada Liturgia”. In Documentos do Concílio Ecumênico Vaticano II, $3^{\text {a }}$ ed., Paulus, São Paulo, 2004, pp. 35-36. Ao longo do artigo utilizaremos a sigla SC seguido do número do parágrafo (SC 5).

${ }^{25}$ LG 7.
} 
Existe, assim, uma única humanidade, um único povo reunido (Ecclesia-Qahãl), que, embora distinto e com experiências próprias, são os eleitos de Deus, filhos no Filho ${ }^{26}$, onde o Verbo é e será tudo em todos (1Cor 15,28): Deus quer salvar todos os homens e fazer com que cheguem ao conhecimento da verdade $(1 \mathrm{Tm} 2,4)$. Para Edith, a maternidade universal da Igreja exige que ela se comporte historicamente e socialmente de forma igual com todos os homens e mulheres, estando eles próximos ou distantes. Seu cuidado não pode se limitar aos que geograficamente estão unidos ao seu corpo visível pelo batismo. Isso porque a visibilidade não delimita e nem esvazia a autonomia salvífica do Espírito:

O Espírito sopra onde quer. Esse Espírito criou todas as formas antigas e deve criar todas as formas novas. Sem Ele, não haveria nem Liturgia nem Igreja ${ }^{29}$.
Com efeito, já que por todos morreu Cristo e que a vocação última de todos os homens é realmente uma só, a saber, a divina, devemos acreditar que o Espírito Santo dá a todos a possibilidade de se associarem a esse mistério pascal por um modo só de Deus conhecido [...] em cujos corações a graça opera ocultamente ${ }^{30}$.

A condição de remido insere todo ser humano na Igreja de Cristo e essa condição se expressa existencial e histórica através da busca a verdade. A busca da verdade é um dos sinais que nos permitem identificar a filiação divina, paradigma antropológico da humanidade: Eu sou o caminho, a verdade e a vida (Jo 14,6). Para Edith, esse desejo da verdade, que une todo homem e mulher a Cristo e, consequentemente, a Igreja, é elemento salvífico, portanto, tem caráter batismal. Com isso, entende-se melhor o pensamento da teóloga com a qual abrimos o artigo:

\footnotetext{
${ }^{26}$ JOÃO PAULO II, Discurso do papa João Jaulo II durante a vigília de oração no Santuário de Nossa Senhora de Fátima. Fátima, 12 de maio de 1991. Disponível em: <http://www.vatican. va/holy_father/john_paul_ii/speeches/1991/may/documents/hf_jp-ii_spe_19910512_veglia-fatima_po.html $>$. Acessado em 15 de julho de 2011.

${ }^{27}$ STEIN, E. A oração da Igreja. Agir, Rio de Janeiro, 1958, pp. 49-50.

${ }^{28}$ CONCÍLIO ECUMÊNICO VATICANO II. “Constituição Pastoral Gaudium et Spes sobre a Igreja no mundo de hoje”. In Documentos do Concílio Ecumênico Vaticano II, $3^{a}$ ed., Paulus, São Paulo, 2004, p. 565.
} 
Nunca gostei de pensar que a misericórdia de Deus fosse apenas aos confins da Igreja visível. Deus é a verdade. Quem procura a verdade procura Deus, quer o saiba ou não $0^{29}$.

Agora precisamos recordar que naqueles tempos pré-conciliares em que viveu Edith, muitos membros da Igreja comportavam-se como mãe apenas para os cristãos católicos excluindo os não católicos e os não batizados. Faltava-lhes essa compreensão da maternidade universal e da autonomia salvífica de Deus. Enfim, muitas escolhas históricas contradiziam a essência da Igreja e o mandato de Cristo (Mc 16,15).

Portanto, a eclesiologia de Edith Stein é de fronteira. Coincidentemente, a figura feminina e esponsal será uma das mais utilizadas durante o Concílio Vaticano II para explicar a relação de Cristo com a Igreja ${ }^{30}$ e para recuperar a universalidade do Reino e a maternidade eclesial como sacramento da verdade e da salvação ${ }^{31}$.

\section{Ecclesia semper reformanda}

A missão da Igreja se realiza na medida em que ela vive a sua identidade de esposa do Esposo e exerce sua maternidade universal sobre todos os homens e mulheres, ou seja,

a missão da Igreja como Sponsa Christi é estar ao seu lado realizando com ele a obra da Salvação ${ }^{34}$.
Realmente, nesta grande obra, pela qual Deus é perfeitamente glorificado e os homens santificados, Cristo sempre associa a si a sua Igreja, sua amadíssima esposa ${ }^{35}$.

Como a salvação de Cristo acontece nas pessoas, também em suas realidades históricas, encaminhando o ser humano ao definitivo (escatológico), como colaboradora na obra da salvação, a Igreja, que é o reino de Deus nesse

${ }^{29}$ SCIADINI, P., Vida e novena - Santa Teresa Benedita da Cruz. Edições Carmelitanas, São Roque, s/d, p. 23.

${ }^{30}$ Cf. LG 6.

${ }^{31}$ Cf. CONCÍLIO ECUMÊNICO VATICANO II. "Declaração Dignitatis Humanae sobre a liberdade religiosa”. In Documentos do Concílio Ecumênico Vaticano II, $3^{\mathrm{a}}$ ed.. Paulus, São Paulo, 2004 , p. 413.

${ }^{32}$ STEIN, E., A mulher - sua missão segundo a natureza e a graça. EDUSC, Bauru, 1999, p. 263.

${ }^{33}$ SC 7. 
mundo, precisa ter em conta as transformações de tudo o que é terreno; Por isso, não pode esquecer ingenuamente que a Igreja tem uma história, que seu lado humano precisa desenvolver-se como tudo o que é humano ${ }^{34}$, ou seja, a missão de anunciar de instaurar o reino de Cristo e de Deus em todas as gentes $^{35}$, exige a coexistência de verdades eternas a serem conservadas sem concessões e de uma elasticidade incomparável na adaptação às condições e necessidades de cada época ${ }^{36}$.

Como mãe da humanidade, a missão da Igreja é cuidar dessa chama da verdade presente em todo ser humano e protegê-la de qualquer vento que possa apagá-la ${ }^{37}$.

Hoje em dia, milhões de crianças estão sem lar e órfãos, apesar de terem uma casa paterna e uma mãe. Elas têm fome de amor e esperam uma mão que as guie [...] como poderia a nossa grande mãe, a Santa Igreja, deixar de abrir os braços em par para apertar contra seu coração esses seres preferidos do senhor? Mas para isso ela precisa de braços e corações humanos, de braços e corações maternais ${ }^{38}$.

Edith exige que a Igreja, esposa de Cristo, viva em constante renovação e adaptação, fiel a sua vocação, revendo se suas escolhas, atos e decisões são reflexos de uma mãe amorosa ou de uma mulher em desarmonia, que inibe e paralisa, onde a alegria de servir é substituída pela vontade de dominar ${ }^{39}$.

Eu sei que para muitos pode parecer um desejo por demais radical. Para a maioria, isto significa, começar de novo, uma reorganização de toda a vida interna e externa. Mas deve ser assim! Na nossa vida deve-se criar espaço para o Cristo eucarístico, para que ele possa transformar a nossa vida na sua, será que é exigir demais? Da auto-suficiência de um "bom católico", que "cumpre seus deveres", que "lê um bom jornal" e que "vota certo", mas que pratica o que ele quer, há ainda um longo caminho até chegar a viver na mão e da mão de Deus ${ }^{40}$.

\footnotetext{
${ }^{34}$ STEIN, E., A mulher - sua missão segundo a natureza e a graça. EDUSC, Bauru, 1999, p. 181.

${ }^{35}$ Cf. LG 5.

${ }^{36}$ STEIN, E., A mulher - sua missão segundo a natureza e a graça. EDUSC, Bauru, 1999, p. 171.

${ }^{37}$ STEIN, E., A mulher - sua missão segundo a natureza e a graça. EDUSC, Bauru, 1999, p. 266.

${ }^{38}$ STEIN, E., A mulher - sua missão segundo a natureza e a graça. EDUSC, Bauru, 1999, p. 277.

${ }^{39}$ Cf. STEIN, E., A mulher - sua missão segundo a natureza e a graça. EDUSC, Bauru, 1999, p. 59.

${ }^{40}$ STEIN, E., O mistério do natal. EDUSC, Bauru, 1999, pp. 28-29.
} 
Podemos, agora perguntar-nos: Não foi o Concílio Vaticano II justamente essa auto-análise, um processo terápico para a Igreja? Portanto, estaria Edith Stein, a judia carmelita, sugerindo o aggiornamento conciliar e antecipando a retomada do lex credendi-lex vivendi?

\section{Apontamentos finais}

Edith Stein é uma pensadora de fronteira, da mesma forma que seu testemunho e escolhas estão à frente de seu tempo. Contudo, ainda não temos obras onde estão sistematizadas sua cristologia integral, sua pneumatologia mistérica, sua liturgia sincera ou sua eclesiologia esponsal e itinerante. Sua clareza nas definições e na abordagem desses temas deixa transparecer um equilíbrio interdependente entre Soteriologia-Cristologia-Antropologia.

Ao concluir esse artigo, descobrimos algumas coordenadas para entender sua eclesiologia (origem, identidade e missão): a Igreja é assembléia convocada, hermenêutica do povo de Israel, Corpo Sacerdotal, humanidade remida, Sponsa Christi, mãe dos remidos e pedagoga da fé. Para nossa surpresa, ou não, estas são mesmas imagens presentes nos documentos do Concílio Vaticano II e por conseqüência nos documentos eclesiais que dele se sucederam: Evangelii Nuntiandi, Diálogo e Anúncio, Dominus Iesu e no Documento de Aparecida: Pelo sopro do Espírito Santo e outros meios de Deus conhecidos, a graça de Cristo pode alcançar todos os que ele remiu, além da comunidade eclesial, de modos diferentes ${ }^{41}$; Explicitar e promover esta salvação já operante no mundo é uma das tarefas da Igreja em respeito às palavras do Senhor: "Sereis minhas testemunhas até os confins da terra" $(\text { At } 1,8)^{42}$. Portanto, Edith Stein está presente com seu pensamento eclesiológico nas entrelinhas do Concílio Vaticano II. Ela também é uma gota que banhou a praia conciliar.

Esse seu olhar mais amplo sobre a Igreja, vendo-a como humanidade remida, faz Edith uma mulher ecumênica e de diálogo. No labirinto da vida, ela viveu o anúncio e o diálogo e descobriu que ser ecumênica significa ser fiel a Igreja de Jesus. Prova disso é que sua madrinha de Batismo, Hedwige Conrad-

\footnotetext{
${ }^{41}$ PONTIFÍCIO CONSELHO PARA O DIÁLOGO INTER-RELIGIOSO; CONGREGAÇÃO PARA A EVANGELIZAÇÃO DOS POVOS. Diálogo e anúncio. Paulinas, São Paulo, 1996, p. 27.

${ }^{42}$ CONSELHO EPISCOPAL LATINO-AMERICANO, Documento de Aparecida - texto conclusivo da $5^{a}$ Conferência Geral do Episcopado Latino-americano e do Caribe. Edições CNBB, Brasília, 2007, p. 111.
} 
-Martius, uma renomada filósofa da época, é uma cristã luterana ${ }^{43}$. Apesar de viver numa Igreja onde predominava um anti-judaísmo teológico, ela afirma pertencer ao povo de Israel, participa das orações na sinagoga e sente orgulho por Jesus de Nazaré ser um judeu ${ }^{44}$.

Por isso, devemos nos inspirar na vocação de Edith, na sua razão genuflexa, e também nos comprometermos com o bem da humanidade. A síntese dramática de nosso século ${ }^{45}$ aprendeu que Cristo é a verdade. Ele é a luz dos povos ${ }^{46}$, ele é a Estrela de Belém que continua a brilhar numa noite escura $^{47}$, nas nossas noites escuras. Ela nos convida a viver nossa vocação na Igreja: é sempre uma aventura responder ao chamado de Deus, porém, Deus merece esse risco ${ }^{48}$.

Por isso, pedimos: Permanece conosco, Senhor! Passos sem ti jamais vamos dar! Vem ser nossa Luz! Que o futuro nos faça ver santa Teresa Benedita da Cruz, Edith Stein - seu testemunho, seu pensamento, sua dedicação à pessoa humana e ao Evangelho - reconhecida com o título de Doutora da Igreja.

\section{Referências Bibliográficas}

BELLO, A.A., A fenomenologia do ser humano - traços de uma filosofia no feminino. EDUSC, Bauru, 2000.

BUBER, M., Eu e Tu. Centauro, São Paulo, 2006.

CONCÍLIO ECUMÊNICO VATICANO II. "Constituição Dogmática Lumen Gentium sobre a Igreja". In Documentos do Concílio Ecumênico Vaticano II, $3^{\text {a }}$ ed.. Paulus, São Paulo, 2004.

CONCÍLIO ECUMÊNICO VATICANO II. "Constituição Pastoral Gaudium et Spes sobre a Igreja no mundo de hoje". In Documentos do Concílio Ecumênico Vaticano II, $3^{\text {a }}$ ed., Paulus, São Paulo, 2004.

\footnotetext{
${ }^{43}$ Cf. HERBSTRITH, W., Edith Stein - a loucura da cruz. Signe, São Paulo, s/d, p. 18.

${ }^{44}$ Cf. MIRIBEL, E., Edith Stein - como o ouro purificado pelo fogo. Santuário, Aparecida, 2001, pp. 69, 97, 98, 122-129. Confira também STEIN, E., Carta ao papa Pio XI sobre a perseguição aos judeus. Münster, 12 de abril de 1933. Disponível em: <>. Acessado em 15 de julho de 2011.

${ }^{45}$ JOÃO PAULO II, Homilia de Beatificação de Santa Teresa Benedita da Cruz. Colônia, $1^{\circ}$ de maio de 1987. Disponível em: <www.vatican.va/holy_father/john_paul_ii/homilies/1987/documents/hf_jp-ii_ hom_19870501_messa-stadio-koln_it.html >. Acessado em 10 de maio de 2011.

${ }^{46}$ LG 1.

${ }^{47}$ STEIN, E., O mistério do natal, EDUSC, Bauru, 1999, p. 15.

${ }^{48}$ HERBSTRITH, W., Edith Stein - a loucura da cruz. Signe, São Paulo, s/d, p. 28.
} 
CONCÍLIO ECUMÊNICO VATICANO II. "Constituição Sacrosanctum Concilium sobre a Sagrada Liturgia". In Documentos do Concílio Ecumênico Vaticano II, $3^{\text {a }}$ ed., Paulus, São Paulo, 2004.

CONCÍLIO ECUMÊNICO VATICANO II. "Declaração Dignitatis Humanae sobre a liberdade religiosa". In Documentos do Concílio Ecumênico Vaticano II, $3^{\text {a }}$ ed., Paulus, São Paulo, 2004.

CONCÍLIO ECUMÊNICO VATICANO II, "Declaração Nostra Aetate sobre as relações da Igreja com as religiões não-cristãs". In Documentos do Concílio Ecumênico Vaticano II. $3^{\mathrm{a}}$ ed.. Paulus, São Paulo, 2004.

CONSELHO EPISCOPAL LATINO-AMERICANO, Documento de Aparecida - texto conclusivo da $5^{a}$ Conferência Geral do Episcopado Latino-americano e do Caribe. Edições CNBB, Brasília, 2007.

HERBSTRITH, W., Edith Stein - a loucura da cruz. Signe, São Paulo, s/d.

JOÃO PAULO II, Discurso do papa João Paulo II durante a vigília de oração no Santuário de Nossa Senhora de Fátima. Fátima, 12 de maio de 1991. Disponível em: <http://www.vatican.va/ holy_father/john_paul_ii/speeches/1991/may/documents/hf_jp-ii_ spe_19910512_veglia-fatima_po.html $>$. Acessado em 15 de julho de 2011.

JOÃO PAULO II, Homilia de Beatificação de Santa Teresa Benedita da Cruz. Colônia, $1^{\circ}$ de maio de 1987. Disponível em: <www.vatican.va/holy_ father/john_paul_ii/homilies/1987/documents/hf_jp-ii_hom_19870501_ messa-stadio-koln_it.html>. Acessado em 10 de maio de 2011.

MIRIBEL, E., Edith Stein - como o ouro purificado pelo fogo. Santuário, Aparecida, 2001.

PONTIFÍCIO CONSELHO PARA O DIÁLOGO INTER-RELIGIOSO; CONGREGAÇÃO PARA A EVANGELIZAÇÃO DOS POVOS. Diálogo e anúncio. Paulinas, São Paulo, 1996.

RAHNER, K., Curso fundamental da fé. Paulinas, São Paulo, 1989.

RATZINGER, J., Jesus de Nazaré, Planeta, São Paulo, 2007.

SCIADINI, P., Vida e novena - Santa Teresa Benedita da Cruz. Edições Carmelitanas, São Roque, s/d.

STEIN, E., Carta ao papa Pio XI sobre a perseguição aos judeus. Münster, 12 de abril de 1933. Disponível em: <http://www.ifen.com.br/monografia/ cynthialeite.pdf $>$. Acessado em 15 de julho de 2011. 
STEIN, E., O mistério do natal. EDUSC, Bauru, 1999.

STEIN, E., A mulher - sua missão segundo a natureza e a graça. EDUSC, Bauru, 1999.

STEIN, E. A oração da Igreja. Agir, Rio de Janeiro, 1958.

Eduardo Dalabeneta

Leigo, mestrando em Teologia PUC/SP, Secretário Geral da Faculdade Dehoniana - Taubaté/SP e-mail: duduscj@yahoo.com.br

Artigo Recebido em 22/08/2011

Artigo Aprovado em 25/11/2011 